\title{
Clozapine Blocks D-Amphetamine-Induced Excitation of Dopamine Neurons in the Ventral Tegmental Area
}

\author{
Wei-Xing Shi*', Xiang-Yang Zhang', Chen-Lun Pun' and Benjamin S Bunney' \\ 'Neuropsychopharmacological Research Unit, Department of Psychiatry, Yale University School of Medicine, New Haven, CT, USA
}

\begin{abstract}
Current antipsychotic drugs are thought to inhibit central dopamine (DA) transmission by blocking DA receptors. Here, we provide evidence that the atypical antipsychotic drug clozapine may produce part of its effect by inhibiting a subset of excitatory inputs to DA neurons. Thus, in chloral hydrate-anesthetized rats, systemic administration of D-amphetamine produced two opposing effects on DA neurons in the ventral tegmental area. Under control conditions, D-amphetamine inhibited the firing of the cell through D2-like receptors. When D2-like receptors were blocked by raclopride, D-amphetamine excited DA neurons, instead of producing no effect. The excitation, expressed as an increase in firing rate and a slow oscillation in firing pattern, was suppressed by the adrenergic $\alpha \mid$ receptor antagonist prazosin, suggesting an involvement of $\alpha$ l receptors. In rats pretreated with the typical antipsychotic drug haloperidol, D-amphetamine also excited DA neurons. However, when given after clozapine, D-amphetamine produced no significant effects. The failure of D-amphetamine to produce an excitation is not due to an incomplete blockade of D2-like receptors by clozapine because co-treatment with clozapine and raclopride also failed to enable the excitatory effect of D-amphetamine. The suggestion that clozapine inhibits the excitatory effect of D-amphetamine is further supported by the finding that clozapine, given after D-amphetamine, reliably reversed D-amphetamine-induced excitation in raclopride-treated rats. Thus, different from raclopride and haloperidol, clozapine may inhibit DA transmission through two additive mechanisms: blockade of DA receptors and inhibition of an amphetamine-sensitive, excitatory pathway that innervates DA neurons.

Neuropsychopharmacology (2007) 32, 1922-1928; doi: I0.1038/sj.npp. I 30 I334; published online I4 February 2007
\end{abstract}

Keywords: schizophrenia; norepinephrine; ventral tegmental area; prefrontal cortex; slow oscillation; firing pattern

\section{INTRODUCTION}

The mesolimbic dopamine (DA) system has been hypothesized to be hyperactive and responsible for positive symptoms in schizophrenia. The cause, however, remains unclear. The finding that schizophrenia is associated with an enhanced ability of D-amphetamine to increase DA release (Laruelle et al, 1996; Laruelle, 2000) suggests that mechanisms sensitive to $\mathrm{D}$-amphetamine may play a role in the proposed DA hyperactivity in schizophrenia.

D-Amphetamine can influence DA release through multiple mechanisms. By binding to DA transporters, D-amphetamine blocks DA reuptake and causes reverse transport (see review by Sulzer et al (2005)). The resulting increase in extracellular DA, in turn, activates various feedback mechanisms, leading to an inhibition of DA cell firing and thus a decrease in impulse-dependent DA release (Bunney et al, 1973; Groves et al, 1975; Bunney

* Correspondence: Professor W-X Shi, Neuropsychopharmacological Research Unit, Department of Psychiatry, Yale University School of Medicine, 300 George Street, Room 8300C, New Haven, CT 065 I I, USA, Tel: + I 203785 4507, Fax: + | 20378545 I0,

E-mail: wei-xing.shi@yale.edu

Received 10 March 2006; revised 13 December 2006; accepted 14 December 2006 and Aghajanian, 1978; Wang, 1981; Shi et al, 2000a). We have recently shown that D-amphetamine also has an excitatory influence on DA neurons through a non-DA mechanism (Shi et al, 2000b, 2004). This non-DA-mediated effect, expressed as an increase in both firing rate and a slow oscillation (SO) in firing pattern, is most evident when the DA-mediated feedback mechanisms are blocked. Results further show that the excitatory effect of D-amphetamine depends on forebrain inputs to DA neurons and requires activation of adrenergic $\alpha 1$ receptors (Shi et al, 2000b, 2004).

The possibility that the $\alpha 1$-mediated excitatory effect of D-amphetamine may contribute to DA release induced by the drug is suggested by the studies by Darracq et al (1998), who have shown that systemic D-amphetamine administration induces two types of DA release in the nucleus accumbens (NAc): functional and non-functional. IntraNAc infusion of D-amphetamine at doses below 4 nmole induces mainly non-functional release since the release is associated with minimal behavioral activation (Vezina et al, 1991; Darracq et al, 1998). The functional release, observed after systemic D-amphetamine injection, is required for Damphetamine to induce locomotor activation and is blocked by the $\alpha 1$ antagonist prazosin given either systemically or locally into the prefrontal cortex (PFC, Darracq et al, 1998). 
When combined, these results raise the possibility that the $\alpha 1$-mediated excitatory effect of D-amphetamine on DA neurons is partially or fully responsible for the functional DA release induced by $\mathrm{D}$-amphetamine and it involves activation of excitatory inputs to DA neurons derived directly or indirectly from the PFC.

The pathway underlying the excitatory effect of $D$ amphetamine may represent an important target for antipsychotic drugs. All current antipsychotic drugs have D2 antagonist properties. Blockade of D2-like receptors not only removes the D2-mediated feedback inhibition, but also enhances the $\alpha 1$-mediated excitation of DA neurons (Shi et al, 2000b, 2004). Both effects promote impulse-dependent DA release, thus counteracting the direct blocking effect of the drug on DA receptors. If, however, an antipsychotic drug can inhibit the excitatory pathway and prevent DA neurons from being activated, it would produce a greater degree of inhibition of DA transmission than it does if it only binds to DA receptors. Furthermore, if the excitatory pathway is directly responsible for the DA hyperactivity in schizophrenia, a selective inhibition of the pathway may be safer than drugs blocking DA receptors indiscriminately in all brain areas. In this study, we examined whether the atypical antipsychotic drug clozapine, the typical antipsychotic drug haloperidol, and the selective D2 antagonist raclopride have different effects on the pathway that mediates the excitatory effect of D-amphetamine on DA neurons.

\section{MATERIALS AND METHODS}

\section{Electrophysiological Recordings}

All procedures were performed in accordance with protocols approved by the Yale Animal Care and Use Committee. Male Sprague-Dawley rats, weighing between 280 and $400 \mathrm{~g}$, were anesthetized with chloral hydrate $(400 \mathrm{mg} / \mathrm{kg}$, i.p., with supplemental doses administered via a lateral tail vein). DA neurons in the ventral tegmental area (VTA) were identified and recorded extracellularly using techniques similar to those described previously (Shi et al, 2000b, 2004; Shi, 2005). Interspike intervals (ISIs) were collected on line via an interface (Lab-PC +, National Instrument, Austin, Texas) to a Windows-based PC computer using in-house software written in LabView for Windows. Only one cell was studied in each rat. Throughout the experiment, body temperature was monitored and maintained at $36-38^{\circ} \mathrm{C}$ with a heating pad.

\section{Drug}

Drugs used in this study were D-amphetamine sulfate, raclopride tartrate, haloperidol, clozapine, and prazosin hydrochloride. All were purchased from Sigma-RBI (St Louis, MO) and administered i.v. through a lateral tail vein. In experiments involving multiple injections, an interval of about 3-10 min was allowed between each injection. Doses refer to the salts where applicable. They were chosen based on previously electrophysiological (eg, Bunney et al, 1973; Welch et al, 1980; Shi et al, 2000b) and receptor binding and behavioral studies (eg, Leysen et al, 1993). Haloperidol was dissolved in dimethyl sulfoxide (DMSO) at $5 \mathrm{mg} / \mathrm{ml}$, prazosin in $25 \%$ poly(ethylene glycol) (PEG, average M.W. 200) at $2.5 \mathrm{mg} / \mathrm{ml}$, and clozapine in a mixture of DMSO (25\%) and PEG (75\%) at $25 \mathrm{mg} / \mathrm{kg}$. Before injection, stock solutions were diluted with distilled water so that the final volume of injection was $0.1-0.2 \mathrm{ml}$. Depending on the weight of the animal, the final concentration of DMSO ranged from 5 to $16 \%$ and that of $\mathrm{PEG}$ ranged from 5 to $48 \%$. Vehicles alone had no significant influence on D-amphetamine-induced effects (Shi et al, 2000b; Zhou et al, 2006). D-Amphetamine and raclopride were dissolved in distilled water.

\section{Data Analysis}

All data analyses were performed in Microsoft Excel using in-house Visual Basic programs. The onset of a burst was identified as two consecutive spikes with an ISI $<80 \mathrm{~ms}$ and the termination of a burst was defined as an ISI $>160 \mathrm{~ms}$ (Grace and Bunney, 1984). Firing rate (average number of spikes per sec), bursting (average number of spikes occurring in bursts per sec), and the variability of firing (CV, SD of ISI expressed as a percentage of the mean interval) were calculated every $10 \mathrm{~s}$. Firing periodicity was analyzed using methods similar to those described previously (Shi et al, 2004; Shi, 2005; Zhou et al, 2006). Briefly, rate histograms and autocorrelograms (autocovariance with a binwidth of $50 \mathrm{~ms}$ over 2048 bins) were constructed based on 2-min recordings obtained under different conditions. Following tapering using the Hanning-Tukey window function (15 windows with $50 \%$ overlap) and removal of the linear trend, the Fast Fourier Transform was performed to yield spectra with a resolution of $0.078 \mathrm{~Hz}$. Spectra obtained from rate histograms and autocorrelograms were qualitatively identical. For simplicity, this study reports only the results from the Fast Fourier Transform of autocorrelograms. To help visualize slow changes, histograms were smoothed using methods described previously (Shi et al, 2004). All spectral results, however, were obtained from non-smoothed data.

Effects of drugs were evaluated by comparing recordings before and after the drug injection using ANCOVA followed by a post hoc Tukey test. Baseline values were the covariates. All measures, including firing rate, bursting, CV, and the $\mathrm{SO}$, were obtained based on analysis of 2-min recordings obtained under different conditions. Spectral data were logtransformed before being subjected to statistical comparison. All numerical results were expressed as mean $\pm \mathrm{SEM}$.

\section{RESULTS}

\section{D-Amphetamine-Induced Inhibition of DA Neurons and its Reversal by Raclopride}

Systemic injection of D-amphetamine $(2 \mathrm{mg} / \mathrm{kg}$, i.v. $)$ inhibited the firing of DA neurons either completely $(n=2)$ or partially $(n=4)$. On average, the firing rate was decreased from $5.5 \pm 0.8$ to $1.7 \pm 0.6$ spikes/s $(n=6)$. In all cells, subsequent injection of the D2-like receptor antagonist raclopride $(0.1-0.2 \mathrm{mg} / \mathrm{kg}$, i.v.) reversed D-amphetamineinduced inhibition and further increased the firing rate to above baseline $\left(7.0 \pm 0.6\right.$ spikes/s, $F_{1,9}=22.6, p<0.001$, Figure 1a). Following raclopride injection, bursting and CV 

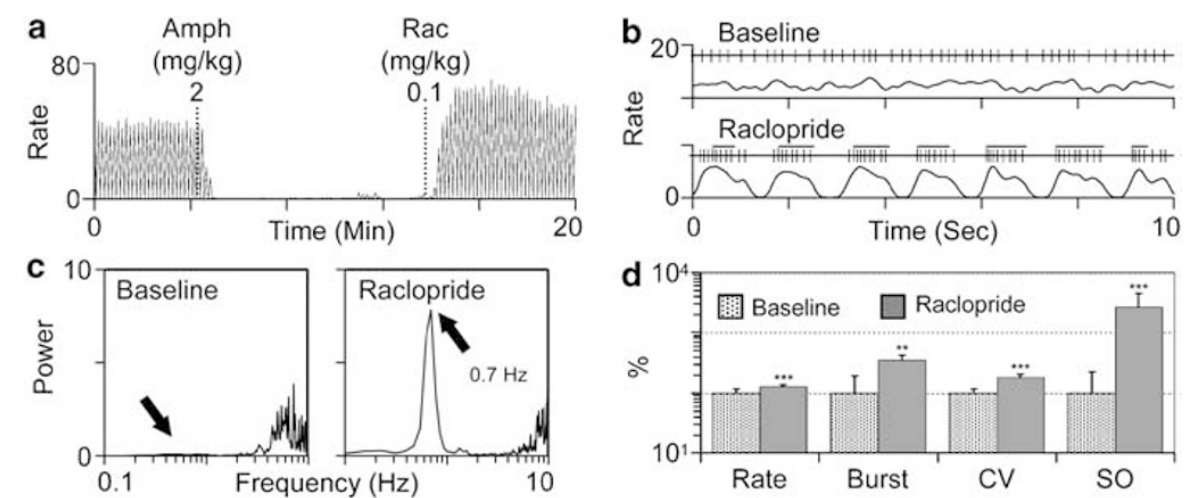

Figure I Inhibition of DA neurons induced by D-amphetamine (Amph) and its reversal by raclopride. (a) Typical rate histogram (spikes/I0 s, binwidth: $10 \mathrm{~s}$ ) showing an inhibition of a VTA DA neuron by D-Amph and the reversal of the inhibition by raclopride (Rac). Note that Rac not only reversed the inhibition, but further increased the firing rate to above baseline. (b) Segments of spike trains and corresponding smoothed, 50-ms-binwidth rate histograms (spikes/s) of the same cell obtained during baseline conditions and after Rac injection. Horizontal bars above the spike train indicate bursts defined by the ' $80 /$ 160 ms' criteria (see Materials and methods). Rac injection changed the firing pattern of the cell from irregular single-spike firing to rhythmic bursting. Note, however, that most burst-like events overlapped only partially with the bursts defined by the ' $80 / 160$ ms' criteria. The rate histograms show that Rac injection induced a SO in firing rate. (c) Power spectra from the same cell confirming the presence of a 0.7- $\mathrm{Hz} \mathrm{SO}$ following Rac injection (arrow). In this and following figures, the amplitude of a spectral peak is expressed as percent of the total power so that the sum of all peaks equals I00. (d) Summary bar graph showing that firing rate, bursting, the variability of firing $(\mathrm{CV})$, and the $\mathrm{SO}\left(\mathrm{P}_{0.5-1.5 \mathrm{~Hz}}\right)$ were all increased following Rac reversal of D-Amph-induced inhibition. Dotted and solid bars are values obtained under baseline conditions and after Rac, respectively. All values are expressed as percent of baseline. *** $<0.01$, ***** $p<0.00$ I compared to baseline.

were also increased compared to baseline (number of spikes occurring in bursts: from $1.4 \pm 1.3$ to $4.8 \pm 1.0$ spikes/s, $\mathrm{F}_{1,9}=19.0, \quad p<0.01 ; \mathrm{CV}$ : from $40.8 \pm 7.1$ to $73.7 \pm 9.2 \%$, $\mathrm{F}_{1,9}=27.3, p \leqslant 0.001$, Figure $1 \mathrm{~b}$ and $\left.\mathrm{d}\right)$. These results were similar to those reported previously (Shi et al, 2000b).

In this study, we further examined the change in firing pattern induced by raclopride injection. As shown in Figure $1 \mathrm{~b}$ and $\mathrm{c}$, raclopride injection also induced rhythmic bursting. Spectral analysis suggests that the pattern of activity can also be described as a SO in firing rate. The frequency of the SO corresponds to the frequency of the burst-like events, whereas the amplitude of the SO is correlated with both the number and frequency of spikes within each event. On average, the amplitude of the SO, measured by the mean relative spectral power between 0.5 and $1.5 \mathrm{~Hz}\left(\mathrm{P}_{0.5-1.5 \mathrm{~Hz}}\right)$, was increased from $0.03 \pm 0.01 \%$ under baseline conditions to $0.80 \pm 0.38 \%$ after raclopride injection $\left(\mathrm{F}_{1,9}=28.5, p<0.001\right.$, Figure $\left.1 \mathrm{~d}\right)$.

\section{D-Amphetamine-Induced Excitation of DA Neurons}

Previous studies suggest that the increase in firing rate seen after raclopride in the above experiment is not a direct effect of raclopride. Instead, it is an effect of D-amphetamine unmasked when the D2-mediated inhibition is blocked by raclopride (Shi et al, 2000b, 2004). Confirming this suggestion, raclopride $(0.1-0.2 \mathrm{mg} / \mathrm{kg}$, i.v.) alone produced only a small effect on firing rate (from $4.9 \pm 0.3$ to $5.2 \pm 0.4$ spike/s, $n=16, p=0.32$, post hoc Tukey test), bursting (from $1.1 \pm 0.4$ to $1.6 \pm 0.5$ spikes in bursts/s, $p=0.23$ ), $\mathrm{CV}$ (from $50.2 \pm 6.0$ to $54.5 \pm 6.5 \%, p=0.44)$, and SO $\left(\mathrm{P}_{0.5-15 \mathrm{~Hz}}\right.$ : from $0.3 \pm 0.2$ to $0.4 \pm 0.2 \%, p=0.39$ ). Subsequent $\mathrm{D}-$ amphetamine injection $(1 \mathrm{mg} / \mathrm{kg}$, i.v. $)$ significantly increased firing rate in $13 / 16$ cells tested, decreased it in two cells, and produced no change in the remaining cell. The Pearson correlation analysis shows that the effect of D-amphetamine is only very weakly correlated with baseline firing rate $(r=-0.14)$. When data from all cells were pooled, the firing rate was significantly increased by D-amphetamine (from $5.2 \pm 0.4$ to $6.7 \pm 0.4$ spikes $/ \mathrm{s}, n=16$, $p<0.001)$. In all cells, D-amphetamine increased the SO $\left(\mathrm{P}_{0.5-15 \mathrm{~Hz}}\right.$ : from $0.4 \pm 0.2$ to $\left.1.2 \pm 0.4 \%, p<0.001\right)$ as well as bursting (from $1.6 \pm 0.5$ to $4.9 \pm 0.7$ spikes/s, $p<0.001$ ) and CV (from $54.5 \pm 6.5$ to $75.8 \pm 8.1 \%, p<0.001$ ). Figure 2 shows recordings from two DA neurons; one showed an increase in firing rate in response to D-amphetamine injection (Figure 2, a1-a3) and one showed a decrease (Figure 2, b1-b3). In both cells, the SO was increased following D-amphetamine injection.

\section{Effects of Haloperidol and Clozapine}

Both haloperidol and clozapine are D2-like receptor antagonists. To determine whether they mimic the effect of raclopride, enabling D-amphetamine to excite DA neurons, rats were treated with haloperidol $(0.1-0.2 \mathrm{mg} /$ $\mathrm{kg}$, i.v.) or clozapine $(4-8 \mathrm{mg} / \mathrm{kg}$, i.v.) and then given D-amphetamine $(1 \mathrm{mg} / \mathrm{kg}$, i.v.). In haloperidol-treated rats, D-amphetamine increased firing rate in $7 / 11$ cells (from $4.3 \pm 0.4$ to $5.4 \pm 0.4$ spikes/s, $n=7, p<0.05$ ), produced no effect in one cell, and decreased firing rate in the remaining three cells. Again, the effect of D-amphetamine was only weakly correlated with baseline firing rate $(\mathrm{r}=-0.29)$. On average, the firing rate after $\mathrm{D}$-amphetamine $(5.3 \pm 0.3)$ was significantly higher than baseline $(4.4 \pm 0.4, p<0.01)$, but not significantly different from values observed after haloperidol $(4.7 \pm 0.3, p=0.1)$. Bursting, $\mathrm{CV}$, and the SO were all significantly increased by $\mathrm{D}$-amphetamine compared to pre-amphetamine levels (burst: from $0.63 \pm 0.25$ to $2.14 \pm 0.52$ spikes/s, $p<0.001$; CV: from $48.1 \pm 6.1$ to $67.1 \pm$ $7.7 \%, p \leqslant 0.001 ; \mathrm{P}_{0.5-1.5 \mathrm{~Hz}}$ : from $0.19 \pm 0.06$ to $0.8 \pm 0.27 \%$, $p<0.01$, Figure $3 \mathrm{a}$ and $\mathrm{c}$ ).

In clozapine-treated rats, $\mathrm{D}$-amphetamine $(1 \mathrm{mg} / \mathrm{kg}$, i.v. $)$ decreased firing rate in $12 / 18$ cells, increased in three cells, 

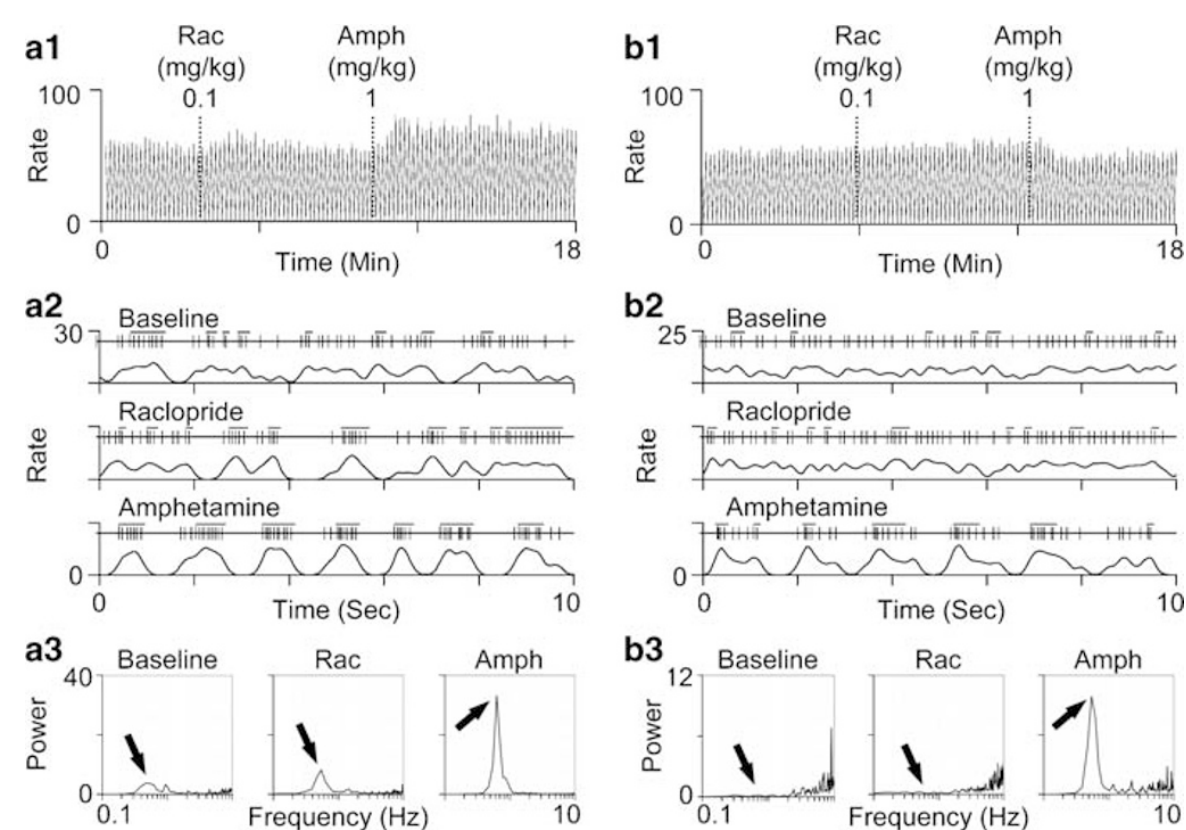

Figure 2 The excitatory effect of D-Amph on DA neurons. (al, bl) Rate histograms (binwidth: I0s) from two VTA DA neurons recorded in two different rats. In both rats Rac was given first and then followed by D-Amph. Cell A showed an increase in firing rate in response to D-Amph injection, whereas Cell B showed a decrease. (a2, b2) Segments of spike trains and smoothed, 50-ms-binwidth rate histograms (spikes/s) showing that D-Amph increased bursting and the SO in both cells. (a3, b3) Power spectra from the same cells confirming an increase in the SO induced by D-Amph (arrows).
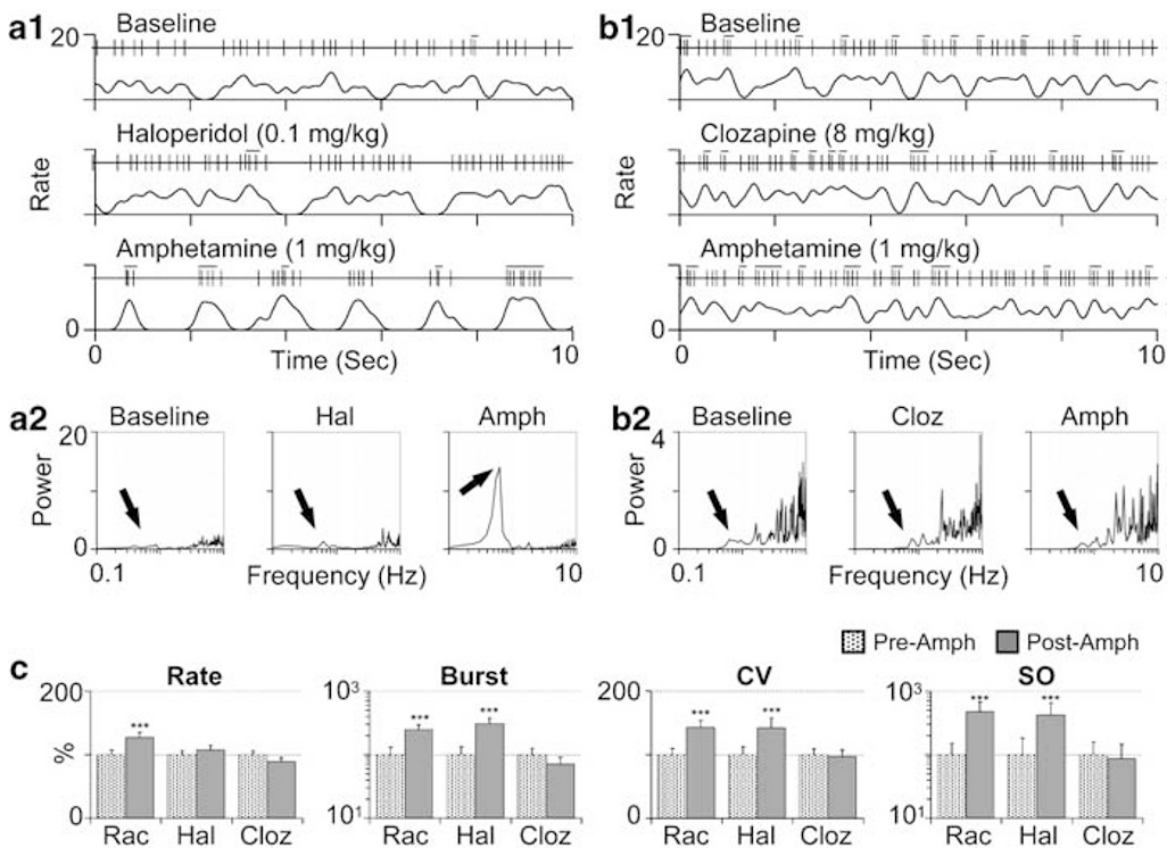

Figure 3 Haloperidol, but not clozapine, enables D-Amph to excite DA neurons: (a l, bl) Segments of spike trains and smoothed, 50-ms-binwidth rate histograms of two DA neurons recorded from two different rats. In Cell A, D-Amph, given after haloperidol (Hal), increased firing rate, bursting, and SO. In Cell B, D-Amph, given after clozapine (Cloz), produced no significant effect on all three measures. (a2, b2) Power spectra confirming the increase in the SO induced by D-Amph in Cell A, but not in Cell B (arrows). (c) Summary bar graphs showing that D-Amph increased bursting, CV, and the SO in rats pretreated with Rac or haloperidol, but not with clozapine. Dotted and solid bars are values obtained before and after D-Amph, respectively. All values are expressed as percent of the measure before D-Amph. ${ }^{*} * * * 0.001$ compared to pre-Amph values.

and produced no change in remaining three cells. On average, D-amphetamine produced a small and statistically insignificant decrease in firing rate (from $5.3 \pm 0.3$ to $4.7 \pm 0.3$ spikes/s, $n=18, \quad p=0.2$ ). Bursting, $\quad \mathrm{CV}$ and
$\mathrm{P}_{0.5-1.5 \mathrm{~Hz}}$ were also unchanged (burst: from $1.9 \pm 0.5$ to $1.3 \pm 0.4$ spikes /s, $p=0.51 ; \mathrm{CV}$ : from $58.6 \pm 5.6$ to $57.0 \pm$ $6.1 \%, p=0.92 ; \mathrm{P}_{0.5-1} 5 \mathrm{~Hz}$ : from $0.62 \pm 0.28$ to $0.69 \pm 0.24 \%$, $p=0.88$, Figure $3 \mathrm{~b}$ and $\mathrm{c}$ ). Figure $3 \mathrm{c}$ summarizes results 
from all cells. For comparison, the figure also includes results from raclopride-treated rats.

\section{Effects of D-Amphetamine in Rats Pretreated with Both Clozapine and Raclopride}

Clozapine is a weak D2-like receptor antagonist (eg, Leysen et al, 1993). To test whether the failure of D-amphetamine to excite DA neurons in clozapine-treated rats is due to an incomplete blockade of D2-like receptors by clozapine, rats $(n=10)$ were pretreated with both clozapine $(4 \mathrm{mg} / \mathrm{kg}$, i.v. $)$ and raclopride $(0.1 \mathrm{mg} / \mathrm{kg}$, i.v.). Subsequent injection of D-amphetamine produced no significant effect on all four measures of DA cell activity (rate: from $5.0 \pm 0.6$ to $5.7 \pm 0.6$ spikes/s, $p=0.08$, burst: from $1.9 \pm 0.6$ to $2.9 \pm 0.7$ to spikes in bursts/s, $p=0.10$; CV: from $57.9 \pm 5.8$ to $63.7 \pm 6.9 \%, \quad p=0.43 ; \quad \mathrm{P}_{0.5-1.5 \mathrm{~Hz}}:$ from $0.56 \pm 0.26$ to $0.84 \pm 0.36 \%, p=0.06$, Figure $4 \mathrm{a})$. Figure $4 \mathrm{c}$ compares the effect of D-amphetamine in rats pretreated with raclopride alone, clozapine alone, and clozapine plus raclopride, respectively.
In a separate group of rats $(n=5), \mathrm{D}$-amphetamine $(1 \mathrm{mg} /$ $\mathrm{kg}$, i.v.) was given after the $\alpha 1$ antagonist prazosin $(0.5 \mathrm{mg} /$ $\mathrm{kg}$, i.v.) and raclopride $(0.1 \mathrm{mg} / \mathrm{kg}$, i.v. $)$. D-Amphetamine produced no significant effects on all four measures of DA cell activity (rate: from $4.8 \pm 0.5$ to $5.4 \pm 0.5$ spikes $/ \mathrm{s}$, $p=0.37$; bursting: from $0.18 \pm 0.12$ to $0.46 \pm 0.27$ spikes in bursts/s, $p=0.28$; CV: from $30.4 \pm 5.0$ to $29.5 \pm 5.1 \%, p=$ $0.99 ; \mathrm{P}_{0.5-1.5 \mathrm{~Hz}}$ : from $0.02 \pm 0.01$ to $0.01 \pm 0.01 \%, p=0.99$, Figure $4 \mathrm{~b})$.

\section{Reversal of D-Amphetamine-Induced Excitation by Clozapine}

To confirm further that clozapine inhibits the mechanism underlying the excitatory effect of $\mathrm{D}$-amphetamine, the drug was administered after D-amphetamine $(1 \mathrm{mg} / \mathrm{kg}$, i.v.) in raclopride-pretreated rats $(0.1 \mathrm{mg} / \mathrm{kg}$, i.v., $n=9)$. In all cells tested, the increases in firing rate, bursting, $\mathrm{CV}$, and the $\mathrm{SO}$ induced by $\mathrm{D}$-amphetamine were reversed by a low dose of clozapine (2 mg/kg, i.v., Figure 5).
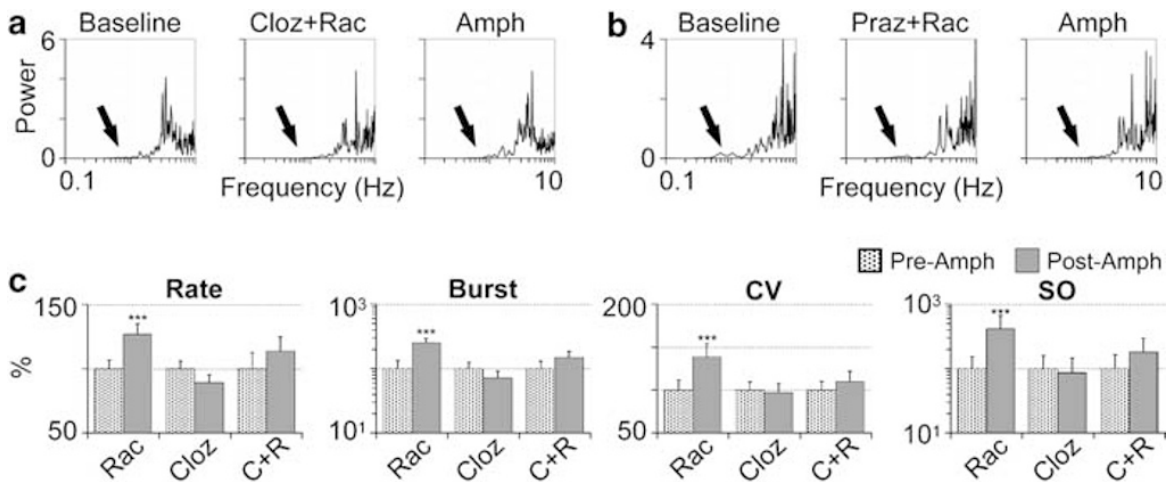

Figure 4 Clozapine mimics the effect of prazosin, blocking the excitatory effect of D-Amph. (a, b) Power spectra from two DA neurons recorded in two different rats showing that D-Amph (Amph I mg/kg, i.v.) produced no significant effect on the SO when given after clozapine (Cloz, $4 \mathrm{mg} / \mathrm{kg}$, i.v.) plus Rac $(0.1 \mathrm{mg} / \mathrm{kg}$, i.v.), or after prazosin (Praz, $0.5 \mathrm{mg} / \mathrm{kg}$, i.v.) plus Rac. (c) Summary bar graphs showing that D-Amph increased firing rate, bursting, CV, and SO in rats pretreated with Rac, but not in rats pretreated with clozapine (Cloz) or with clozapine and Rac $(C+R)$. Dotted and solid bars are values before and after D-Amph injection, respectively. All are expressed as percent of pre-Amph values. $* * * *<<0.00$ I compared to pre-Amph values.
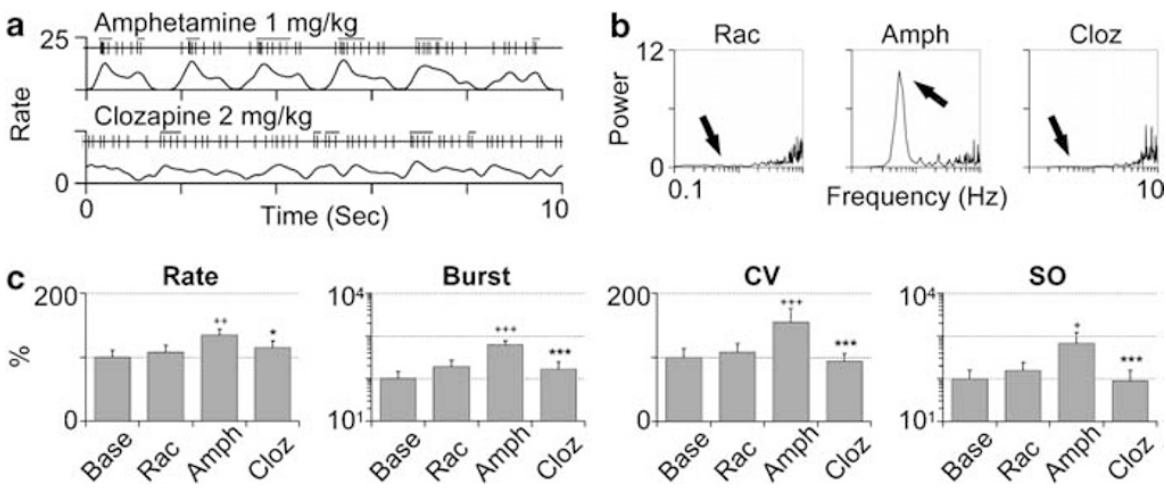

Figure 5 Clozapine reverses D-Amph-induced excitation of DA neurons. (a) Segments of spike trains and smoothed rate histograms from the same DA neuron shown in Figure $2 b$ showing that clozapine, given after D-Amph, reversed the increase in bursting and SO induced by D-Amph in a Rac-pretreated rat. (b) Power spectra from the same neuron confirming the increase in the SO (arrow) induced by D-Amph (given after Rac) and its reversal by clozapine (Cloz). (c) Summary bar graphs showing the reversal by clozapine of the increase in firing rate, bursting, CV, and the SO induced by D-Amph in Rac-treated rats. All values are expressed as percent of baseline (Base). ${ }^{+} p<0.05,{ }^{++} p<0.01,{ }^{++}{ }^{+} p<0.001$ compared to values obtained after Rac injection. $* p<0.05$, **** $p<0.00$ I compared to values obtained after D-Amph injection. 


\section{DISCUSSION}

This study confirms that D-amphetamine has two opposing effects on DA neurons: a DA-mediated inhibition and a non-DA-mediated excitation, and further shows that clozapine, but not haloperidol and raclopride, blocks the excitatory effect of D-amphetamine. These results suggest that clozapine inhibits DA transmission by at least two different and additive mechanisms: binding to DA receptors and inhibiting a subset of excitatory inputs to DA neurons. Previous evidence suggests that these inputs may be derived directly or indirectly from the PFC.

It has been known for decades that DA antagonists, given after D-amphetamine, not only reverse the inhibition of DA neurons induced by $\mathrm{D}$-amphetamine, but further increase the firing rate of the cell to above pre-drug baseline (Bunney et al, 1973). The latter effect was initially thought to be a direct effect of a DA antagonist (Bunney et al, 1973) enhanced by D-amphetamine (Welch et al, 1980). Recent evidence suggests that it is an excitatory effect of Damphetamine uncovered when D2-like receptors are blocked (Shi et al, 2000b). Results further show that the effect is associated with an increase in not only firing rate, but also bursting (Shi et al, 2000b). In this study, we confirmed these findings. However, we found that most burst-like events seen during $\mathrm{D}$-amphetamine-induced excitation overlapped only partially with the traditionally defined bursts, suggesting that the standard burst analysis provides only a partial estimate of the effect of D-amphetamine. Using spectral analysis, this study showed that the change in firing pattern induced by $\mathrm{D}$-amphetamine can also be described as an increase in a $\mathrm{SO}$ in firing frequency.

In most DA neurons recorded in raclopride-treated rats, D-amphetamine increased both firing rate and the SO. In a subset of cells, however, D-amphetamine increased the SO without increasing the firing rate, suggesting that in DA neurons, firing rate and pattern can be regulated independently. Consistent with this suggestion, independent changes in bursting and firing have been described. For example, PFC activation and inactivation have been shown to increase and decrease, respectively, the level of bursting without altering the firing rate of DA neurons (Svensson and Tung, 1989; Murase et al, 1993). Our previous evidence suggests that $\alpha 1$ receptors play a more significant role in amphetamine's effect on firing pattern than on firing rate (Shi et al, 2000b; Zhou et al, 2006). In haloperidol-treated rats, D-amphetamine also increased firing rate in only a subpopulation of VTA DA neurons. In all cells, however, D-amphetamine, given after haloperidol, significantly increased the SO. The increase in the SO may contribute importantly to the enhanced ability of $\mathrm{D}$-amphetamine to increase DA release in haloperidol-treated rats (Pehek, 1999) since stimulation of DA neurons mimicking rhythmic bursting, a typical form of the SO, induces much more DA release than stimulation applied at the same overall frequency, but in an evenly spaced manner (Gonon, 1988).

Clozapine is also a D2-like receptor antagonist, albeit weaker than most typical antipsychotic drugs. However, unlike haloperidol and raclopride, clozapine failed to enable D-amphetamine to excite DA neurons. This finding is consistent with the previous observation that clozapine, given after $\mathrm{D}$-amphetamine, reverses the inhibition induced by D-amphetamine without causing the firing rate to exceed baseline (Bunney and Aghajanian, 1975; Welch et al, 1980). The failure of $\mathrm{D}$-amphetamine to produce an excitation is not due to an incomplete blockade of D2-like receptors by clozapine because co-treatment with clozapine and raclopride also failed to enable D-amphetamine to excite DA cells. The finding that clozapine, given after D-amphetamine, reliably reversed the excitation induced by $\mathrm{D}-$ amphetamine in raclopride-treated rats further suggests that clozapine inhibits the pathway mediating the excitatory effect of D-amphetamine. Supporting this suggestion is the fact that clozapine has a high affinity for $\alpha 1$ receptors (Leysen et al, 1993; Cahir and King, 2005). We have previously shown that the excitatory effect of D-amphetamine depends on activation of $\alpha 1$ receptors since it is blocked by $\alpha 1$ antagonists, including prazosin (Shi et al, $2000 \mathrm{~b}, 2004)$. Studies by Darracq et al (1998) further suggest that $\alpha 1$ receptors in the PFC may play a key role in the excitatory effect of D-amphetamine (see Introduction).

Part of clozapine's blocking effect may also be related to its binding to 5-HT2A receptors (Meltzer et al, 1989). Blockade of 5-HT2A receptors by SR 46349B has been shown to mimic the effect of prazosin, inhibiting both the functional DA release and locomotor activation induced by D-amphetamine (Auclair et al, 2004). Different from prazosin, however, SR46349B is effective only when given systemically or locally into the VTA. Local infusion of the drug into the PFC is ineffective. Thus, the excitatory effect of D-amphetamine on DA neurons may require concurrent activation of $\alpha 1$ and 5-HT2A receptors in the PFC and VTA, respectively, and clozapine may inhibit the effect of Damphetamine by blocking both $\alpha 1$ and 5-HT2A receptors. In preliminary experiments, we found that the $5-\mathrm{HT} 2 \mathrm{~A} / 2 \mathrm{C}$ antagonist ritanserine failed to prevent $\mathrm{D}$-amphetamine from exciting DA neurons (Shi et al, 2000b). In those experiments, however, only firing rate and bursting were measured. Thus, whether or not ritanserine and other 5-HT2A antagonists can inhibit the enhancing effect of D-amphetamine on the SO remains to be determined.

Haloperidol also binds to $\alpha 1$ receptors with an affinity only slightly lower than that of clozapine (Cahir and King, 2005). However, when examined in vivo, haloperidol $(0.016-0.23 \mathrm{mg} / \mathrm{kg})$ is much less effective in blocking $\alpha 1$ receptors compared to behaviorally comparable doses (0.5$11 \mathrm{mg} / \mathrm{kg}$ ) of clozapine (Gallager and Aghajanian, 1976; Leysen et al, 1993). Haloperidol also has a low affinity for 5HT2A receptors (eg, Meltzer et al, 1989; Leysen et al, 1993).

Imaging studies show that, at therapeutic doses, haloperidol produces a much higher D2 receptor occupancy than does clozapine (Farde et al, 1992). The occupancy measure, however, may reflect an interaction of a drug with tonic levels of extracellular DA. During synaptic activation, DA concentrations within the synapse can reach $\mu \mathrm{M}$ ranges (Cragg, 2003). Under such conditions, most antipsychotic drugs, at their therapeutic concentrations (nM ranges, Seeman, 1995), may only partially block D2-like receptors. If, however, a drug can prevent DA neurons from being activated, it would produce a greater inhibition of DA transmission than it does if it only binds to DA receptors. Thus, the ability of clozapine to inhibit excitatory inputs to DA neurons may provide part of the explanation for why the drug can produce its therapeutic effects at a relatively low D2 receptor occupancy. 
The significance of the effect of clozapine is also suggested by the evidence that the pathway underlying the excitatory effect of D-amphetamine may be derived from the PFC (Darracq et al, 1998). PFC control of DA neurons has been suggested to play a critical role in the hyperactivity of DA in subcortical regions in schizophrenia (Weinberger, 1987; Davis et al, 1991; Grace, 1991; Deutch, 1992).

\section{ACKNOWLEDGEMENTS}

This work was supported in part by NIDA DA12944 (WXS), a NARSAD Independent Investigator Award (WXS), and a NARSAD Distinguished Investigator Award (BSB).

\section{REFERENCES}

Auclair A, Blanc G, Glowinski J, Tassin JP (2004). Role of serotonin $2 \mathrm{~A}$ receptors in the $\mathrm{D}$-amphetamine-induced release of dopamine: comparison with previous data on alphalb-adrenergic receptors. J Neurochem 91: 318-326.

Bunney BG, Aghajanian GK (1975). Antipsychotic drugs and central dopaminergic neurons: a model for predicting therapeutic efficacy and incidence of extrapyramidal side effects. In: Sudilovsky A, Gershon S, Beer B (eds). Predictability in Psychopharmacology: Preclinical and Clinical Correlations. Raven Press: New York. pp 225-245.

Bunney BS, Aghajanian GK (1978). D-Amphetamine-induced depression of central dopamine neurons: evidence for mediation by both autoreceptors and a striato-nigral feedback pathway. Naunyn Schmiedebergs Arch Pharmacol 304: 255-261.

Bunney BS, Walters JR, Roth RH, Aghajanian GK (1973). Dopaminergic neurons: effect of antipsychotic drugs and amphetamine on single cell activity. J Pharmacol Exp Ther 185: 560-571.

Cahir M, King DJ (2005). Antipsychotics lack [alpha]1A/B adrenoceptor subtype selectivity in the rat. Eur Neuropsychopharmacol 15: 231-234.

Cragg SJ (2003). Variable dopamine release probability and shortterm plasticity between functional domains of the primate striatum. J Neurosci 23: 4378-4385.

Darracq L, Blanc G, Glowinski J, Tassin JP (1998). Importance of the noradrenaline-dopamine coupling in the locomotor activating effects of D-amphetamine. J Neurosci 18: 2729-2739.

Davis K, Kahn R, Ko G, Davidson M (1991). Dopamine in schizophrenia: a review and reconceptualization. Am J Psychiatry 148: 1474-1486.

Deutch AY (1992). The regulation of subcortical dopamine systems by the prefrontal cortex: interactions of central dopamine systems and the pathogenesis of schizophrenia. J Neural Transm Suppl 36: 61-89.

Farde L, Nordstrom AL, Wiesel FA, Pauli S, Halldin C, Sedvall G (1992). Positron emission tomographic analysis of central D1 and D2 dopamine receptor occupancy in patients treated with classical neuroleptics and clozapine. Relation to extrapyramidal side effects. Arch Gen Psychiatry 49: 538-544.

Gallager DW, Aghajanian GK (1976). Effect of antipsychotic drugs on the firing of dorsal raphe cells. I. Role of adrenergic system. Eur J Pharmacol 39: 341-355.

Gonon FG (1988). Nonlinear relationship between impulse flow and dopamine released by rat midbrain dopaminergic neurons as studied by in vivo electrochemistry. Neuroscience 24: 19-28.

Grace AA (1991). Phasic versus tonic dopamine release and the modulation of dopamine system responsivity: a hypothesis for the etiology of schizophrenia. Neuroscience 41: 1-24.

Grace AA, Bunney BS (1984). The control of firing pattern in nigral dopamine neurons: burst firing. J Neurosci 4: 2877-2890.
Groves PM, Wilson CJ, Young SJ, Rebec GV (1975). Self-inhibition by dopaminergic neurons. Science 190: 522-528.

Laruelle M (2000). The role of endogenous sensitization in the pathophysiology of schizophrenia: Implications from recent brain imaging studies. Brain Res Rev 31: 371-384.

Laruelle M, Abi-Dargham A, van Dyck CH, Gil R, D'Souza CD, Erdos J et al (1996). Single photon emission computerized tomography imaging of amphetamine-induced dopamine release in drug-free schizophrenic subjects. Proc Natl Acad Sci USA 93: 9235-9240.

Leysen JE, Janssen PM, Schotte A, Luyten WH, Megens AA (1993). Interaction of antipsychotic drugs with neurotransmitter receptor sites in vitro and in vivo in relation to pharmacological and clinical effects: role of 5HT2 receptors. Psychopharmacology (Berlin) 112: S40-S54.

Meltzer HY, Matsubara S, Lee JC (1989). Classification of typical and atypical antipsychotic drugs on the basis of dopamine D-1, D-2 and serotonin2 pKi values. J Pharmacol Exp Ther 251: 238-246.

Murase S, Grenhoff J, Chouvet G, Gonon FG, Svensson TH (1993). Prefrontal cortex regulates burst firing and transmitter release in rat mesolimbic dopamine neurons studied in vivo. Neurosci Lett 157: $53-56$.

Pehek EA (1999). Comparison of effects of haloperidol administration on amphetamine-stimulated dopamine release in the rat medial prefrontal cortex and dorsal striatum. J Pharmacol Exp Ther 289: 14-23.

Seeman P (1995). Doapmine receptors: clinical correlates. In: Bloom FE, Kupfer DJ (eds). Pyschopharmacology: The Fourth Generation of Progress. Raven Press: New York. pp 295-302.

Shi WX (2005). Slow oscillatory firing: a major firing pattern of dopamine neurons in the ventral tegmental area. J Neurophysiol 94: 3516-3522.

Shi WX, Pun CL, Smith PL, Bunney BS (2000a). Endogenous DA-mediated feedback inhibition of DA neurons: involvement of both $\mathrm{D}(1)$ - and $\mathrm{D}(2)$-like receptors. Synapse 35: 111-119.

Shi WX, Pun CL, Zhang XX, Jones MD, Bunney BS (2000b). Dual effects of $\mathrm{D}$-amphetamine on dopamine neurons mediated by dopamine and nondopamine receptors. J Neurosci 20: $3504-$ 3511.

Shi WX, Pun CL, Zhou Y (2004). Psychostimulants induce lowfrequency oscillations in the firing activity of dopamine neurons. Neuropsychopharmacology 29: 2160-2167.

Sulzer D, Sonders MS, Poulsen NW, Galli A (2005). Mechanisms of neurotransmitter release by amphetamines: a review. Prog Neurobiol 75: 406-433.

Svensson TH, Tung CS (1989). Local cooling of pre-frontal cortex induces pacemaker-like firing of dopamine neurons in rat ventral tegmental area in vivo. Acta Physiol Scand 136: 135-136.

Vezina P, Blanc G, Glowinski J, Tassin JP (1991). Opposed behavioural outputs of increased dopamine transmission in prefrontocortical and subcortical areas: a role for the cortical D-1 dopamine receptor. Eur J Neurosci 3: 1001-1007.

Wang RY (1981). Dopaminergic neurons in the rat ventral tegmental area. III. Effects of-and-amphetamine. Brain Res Rev 3: 153-165.

Weinberger DR (1987). Implications of normal brain development for the pathogenesis of schizophrenia. Arch Gen Psychiatry 44: 660-669.

Welch JJ, Kim HS, Liebman J (1980). Amphetamine-induced increases in dopaminergic single cell firing rate after haloperidol pretreatment. Correlation with extrapyramidal side effects. Neuropharmacology 19: 371-377.

Zhou Y, Bunney BS, Shi WX (2006). Differential effects of cocaine on firing rate and pattern of dopamine neurons: role of \{alpha\} 1 receptors and comparison with L-dopa and apomorphine. J Pharmacol Exp Ther 317: 196-201. 